\title{
Polypharmacy in Older Patients $\geq 70$ Years Receiving Palliative Radiotherapy
}

\author{
CARSTEN NIEDER ${ }^{1,2}$, BĂRD MANNSĂKER ${ }^{1}$, ADAM PAWINSKI $^{1}$ and ELLINOR HAUKLAND ${ }^{1,2}$ \\ ${ }^{1}$ Department of Oncology and Palliative Medicine, Nordland Hospital Trust, Bod, , Norway; \\ ${ }^{2}$ Department of Clinical Medicine, UiT - The Arctic University of Norway, Troms $\phi$, Norway
}

\begin{abstract}
Background/Aim: Many older cancer patients receive five or more daily medications (polypharmacy). The purpose of this study was to assess the prevalence of polypharmacy in older patients undergoing palliative radiotherapy and its influence on the risk of being unable to complete the prescribed number of fractions, as well as the 30-day mortality and overall survival. Patients and Methods: Retrospective review of 289 patients aged 70 years or older. Results: The median and mean Charlson comorbidity index (11) was 2, ranging between 0-7 (presently treated cancer not included). The median and mean number of daily medications was 7 , ranging between 0-18. Only $27 \%$ of patients used less than 5 daily medications. Corticosteroids were used by 59\% of the patients and opioid analgesics by $55 \%$. Comorbidity, but also symptom severity, as indexed by pain medication, correlated significantly with the prevalence of polypharmacy. In multivariate analysis, neither polypharmacy nor use of corticosteroids or opioid analgesics influenced overall survival. No trends were seen for 30-day mortality or failure to complete radiotherapy. Conclusion: Polypharmacy is a common phenomenon in older patients receiving palliative radiotherapy and it does not predict adverse radiotherapy outcomes.
\end{abstract}

Due to current trends in cancer incidence and demographics, an increasing number of older people are in need of oncological treatment (1). The favorable toxicity profile and high efficacy of radiotherapy make this treatment modality a preferred choice both in curative and palliative settings (2, 3 ). While older patients' eligibility for curative radiotherapy depends on comprehensive multidimensional assessment of

Correspondence to: Carsten Nieder, MD, Department of Oncology and Palliative Medicine, Nordland Hospital Trust, 8092 Bodø, Norway. Tel: +47 75578449, Fax: +47 75534975, e-mail: carsten.nieder@nlsh.no

Key Words: Comorbidity, elderly patients, palliative radiotherapy, polypharmacy, prognostic factors. biological age, organ function and other selection criteria, fewer restrictions are necessary when prescribing palliative regimens, especially short-course radiotherapy, which aims at symptom relief only (4). In daily practice, patients receiving palliative radiotherapy comprise a large group (5), with highly variable survival outcomes and different treatment aims $(6,7)$. Several screening tools have been developed to identify older patients with cancer who are likely to benefit from a complete geriatric assessment. Recently, an optimized tool was presented achieved high sensitivity, high specificity, better homogeneity across cancer types and greater parsimony with only six items needed (8). One of these items was polypharmacy, i.e. five or more medications daily. It has been suggested that greater attention to polypharmacy could lead to improvements in adverse drug events, cost, and possibly quality of life (9). The purpose of our study was to assess the incidence of polypharmacy in older patients undergoing palliative radiotherapy and its influence on the risk of being unable to complete the prescribed number of fractions, as well as the 30-day mortality and overall survival.

\section{Patients and Methods}

Patients. A retrospective single institution analysis of 319 contemporary (2007-2014) consecutive in- and out-patients aged 70 years or older was performed. All were treated with palliative 2-D or 3-D radiotherapy (no stereotactic radiosurgery or stereotactic ablative body radiotherapy), e.g. for bone, lymph node or brain metastases, bleeding from their primary tumor or thoracic symptoms from lung cancer. Common fractionation regimens were $3 \mathrm{~Gy} \times 10$ 13 or 4 Gy $\times 5-6$. Their daily medications were recorded in the hospital's electronic patient records (EPR). As in other studies, polypharmacy was defined as five or more medications daily and extreme polypharmacy as ten or more (8-10). All drugs were taken into account, regardless of route of administration or indication. We excluded 30 out-patients because their medication records were older than 2 weeks when they started radiotherapy. Hematology and blood chemistry results immediately before radiotherapy were also available in the EPR (hemoglobin, leukocyte count, thrombocyte count, albumin, C-reactive protein, creatinine, lactate dehydrogenase, electrolytes). 
Statistical analysis. Survival time was measured from the first day of palliative radiotherapy. We used IBM SPSS Statistics 22 (IBM Corporation, Armonk, NY, USA) for all evaluations. Actuarial survival curves were generated by the Kaplan-Meier method and compared by the log-rank test. For multivariate analysis of survival Cox regression analysis was used (forward conditional method). All factors with significant $p$-value in univariate log-rank tests were carried forward to multivariate regression analysis. Associations between different variables of interest were assessed with the chisquare and Fisher exact probability test. Statistical significance was defined as $p<0.05$ throughout this study in two-sided tests.

\section{Results}

Demographics. The eligible cohort of 289 patients had a median age of 77 years and a range between $70-95$ years (Table I). The median and mean Charlson comorbidity index (11) was 2 (range: 0-7; presently treated cancer not included). The median and mean number of daily medications was 7 (range: 0-18). Only $27 \%$ of the patients used less than 5 medications. Regarding the age strata displayed in Table I, the polypharmacy rate did not increase significantly with age. Corticosteroids were used by $59 \%$ of the patients and opioid analgesics by $55 \%$, including $3 \%$ who received a continuous infusion via a pump.

Polypharmacy correlates with comorbidity and symptom severity. As shown in Table II comorbidity and symptom severity as indexed by pain medication, correlated in a statistically significant manner with the prevalence of polypharmacy. Comparable correlations existed for extreme polypharmacy. Very few patients with Charlson comorbidity index 3 or more used less than five daily medications and none of the patients required analgesia via an infusion pump.

Polypharmacy and survival. Median overall survival was 5 months (147 days). As shown in Figure 1, survival of patients with polypharmacy and extreme polypharmacy was worse (median: 231 and 152, respectively) compared to survival of patients with four or less medications (median: 96 days). However, the observed differences reached statistical significance only when comparing extreme polypharmacy to 0-4 medications.

Prognostic factors for survival. Patients who used corticosteroids had significantly shorter survival than non-users (median 117 vs. 170 days, $p=0.0001$, Kaplan-Meier curves not shown). The same was true for opioid analgesics (median 104 $v s .281$ days, $p=0.0001$ ) and in particular pump administration (median 40 days). Significantly shorter survival was also found in patients with reduced performance status, brain metastases, liver metastases, lung metastases, adrenal gland metastases, higher Glasgow prognostic score (0: normal C-reactive protein and albumin, 1: abnormal C-reactive protein or albumin, 2: abnormal C-reactive protein and albumin) (12), higher Charlson
Table I. Patient characteristics.

\begin{tabular}{|c|c|c|}
\hline Parameter & Number of patients & Percentage \\
\hline Females & 77 & $27 \%$ \\
\hline Males & 211 & $73 \%$ \\
\hline Age $70-74$ years & 86 & $30 \%$ \\
\hline Age $75-79$ years & 103 & $36 \%$ \\
\hline Age $\geq 80$ years & 100 & $35 \%$ \\
\hline No comorbidity & 37 & $13 \%$ \\
\hline Charlson comorbidity index 1 & 46 & $16 \%$ \\
\hline Charlson comorbidity index 2 & 89 & $31 \%$ \\
\hline Charlson comorbidity index $\geq 3$ & 117 & $40 \%$ \\
\hline No use of daily medication & 3 & $1 \%$ \\
\hline 1-4 daily medications & 76 & $26 \%$ \\
\hline 5-9 daily medications & 125 & $43 \%$ \\
\hline$\geq 10$ daily medications & 85 & $29 \%$ \\
\hline Performance status ECOG 0 & 17 & $6 \%$ \\
\hline Performance status ECOG 1 & 71 & $25 \%$ \\
\hline Performance status ECOG 2 & 101 & $35 \%$ \\
\hline Performance status ECOG 3 & 85 & $29 \%$ \\
\hline Performance status ECOG 4 & 15 & $5 \%$ \\
\hline Prostate cancer & 115 & $40 \%$ \\
\hline Breast cancer & 15 & $5 \%$ \\
\hline Lung cancer (small/non-small cell) & $16 / 65$ & $6 / 22 \%$ \\
\hline Bladder cancer & 26 & $9 \%$ \\
\hline Colorectal cancer & 19 & $7 \%$ \\
\hline Other cancers & 33 & $11 \%$ \\
\hline No distant metastases & 46 & $16 \%$ \\
\hline Distant metastases & 243 & $84 \%$ \\
\hline On systemic treatment & 77 & $27 \%$ \\
\hline Glasgow prognostic score 0 & 94 & $33 \%$ \\
\hline Glasgow prognostic score 1 & 132 & $46 \%$ \\
\hline Glasgow prognostic score 2 & 63 & $22 \%$ \\
\hline
\end{tabular}

ECOG, Eastern Cooperative Oncology Group.

comorbidity index and those not on systemic treatment. Patients without distant metastases survived significantly longer than patients with distant metastases (median 262 vs. 127 days, $p=0.01$ ). Patients with prostate, breast or kidney cancer survived significantly longer than those with other cancer types (median 308, 275, 176 days; others: 80-113 days, $p=0.02$ ). Factors such as gender, anemia, other hematology and blood chemistry results, active/previous smoking, and bone metastases were not associated with survival.

In multivariate analysis, neither polypharmacy nor use of corticosteroids or opioid analgesics influenced overall survival (data not shown). Significant prognostic factors were performance status $(p=0.0001)$, favorable cancer type (prostate, breast, kidney; $p=0.0001$ ), absence of distant metastases $(p=0.0001)$, absence of liver metastases $(p=0.01)$ and Glasgow prognostic score $(p=0.008)$.

Polypharmacy and other endpoints. The number of daily medications was neither significantly associated with 30-day mortality nor failure to complete radiotherapy. No trends were seen either (data not shown). 


\section{Discussion}

Multiple and/or inappropriate use of medications in seniors is a significant public health problem and cancer treatment escalates its prevalence and complexity. Although no single polypharmacy cut-point is optimal for predicting multiple adverse events in older people with cancer, the common definition of five or more medications is reasonable for identifying 'at-risk' patients for medication review (13). A study of 234 senior adults with cancer found a mean number of medications of 9 (10). The prevalence of polypharmacy, excessive polypharmacy and potentially inappropriate medication use was $41 \%, 43 \%$ and $51 \%$, respectively. A different study included 2282 patients (advanced cancer pain patients, defined by a need for a World Health Organization analgesic ladder step III opioid) from 17 Centers in 11 European countries (14). They received a mean of 8 drugs. Over one-quarter used 10 or more medications. The drug classes most frequently co-administered with opioids were proton pump inhibitors, laxatives, corticosteroids, paracetamol (acetaminophen), nonsteroidal anti-inflammatory drugs, metoclopramide, benzodiazepines, anticoagulants, antibiotics, anticonvulsants, diuretics and antidepressants. Approximately $45 \%$ of patients received unnecessary or potentially unnecessary drugs, and about $7 \%$ were given duplicate or antagonizing agents. In an Australian study, polypharmacy was also highly prevalent $(57 \%)$ in older people ( $\geq 70$ years) with cancer and associated with impaired physical function and being pre-frail and frail compared to being robust (15) and associated with higher Charlson comorbidity index scores. In one study with 117 patients aged $\geq 65$ years with newlydiagnosed cancer treated at ambulatory oncology clinics at an academic medical center, the prevalence of polypharmacy $(\geq 5$ medications) was as high as $80 \%$ (16). An increase in comorbidity count by one and ECOG performance status by one was associated with an increase in medication use by 0.48 $(p=0.0002)$ and $0.79(p=0.01)$, respectively. This issue might be aggravated by additional use of non-reported complementary or alternative medications (17).

These high prevalence figures prompted us to perform a similar study in patients aged 70 years or older who were treated with palliative radiotherapy, either in an ambulatory or in-patient setting. Comparable to previous studies we did not limit our analysis to one type of cancer. Although most patients with incurable cancer receive comparable supportive and anticancer drugs (analgesics, anti-emetics, chemotherapy, bisphosphonates etc.), a primary cancer-specific study limited, e.g., to prostate cancer may facilitate a better correlation analysis. The median and mean number of daily medications in our study was seven. Only $27 \%$ of patients used less than five medications. Charlson comorbidity index and symptom severity, as indexed by pain medication, correlated with the prevalence of polypharmacy. In

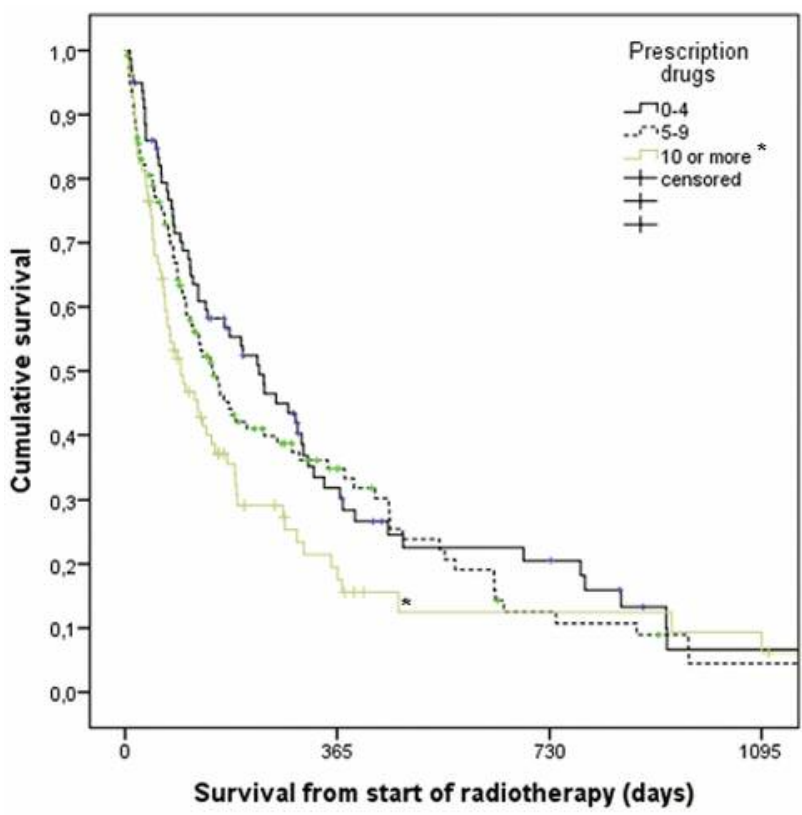

*stat. significant

Figure 1. Overall survival (Kaplan-Meier estimates) for patients with 0-4 daily medications (median: 231 days), 5-9 daily medications (median: 152 days) and 10 or more daily medications (median: 96 days), $p=0.38$ (0-4 vs. 5-9), $p=0.02$ (0-4 vs. $\geq 10), p=0.09$ (5-9 vs. $\geq 10$ ).

multivariate analysis, neither polypharmacy nor use of corticosteroids or opioid analgesics influenced overall survival. Polypharmacy was neither significantly associated with 30-day mortality nor failure to complete radiotherapy. No trends were seen either. These findings are in line with those from other recent oncology studies, which are summarized in Table III. However, some of these studies suggested correlations between polypharmacy and chemotherapy toxicity. Since palliative radiotherapy results in very low rates of serious toxicity, this end-point was not evaluated in our study. Future research should focus on radical radio(chemo)therapy, which has a different side-effect profile. Ideally, quality of life and adverse events would be recorded prospectively.

Even if polypharmacy did not predict adverse radiotherapy outcomes in terms of short survival or failure to complete the prescribed number of fractions, its prevalence was so high that clinical practitioners should be educated about optimal medication use and avoidance of inappropriate medications in order to spare patients unnecessary toxicity and costs. In an Irish study, one week before death one-third of patients continued to be prescribed aspirin, and over one-quarter a statin (22). On the other hand one has to acknowledge that immobilized patients with severe pain often require opioid analgesics combined with a non-opioid and/or co-analgesic, laxatives, anticoagulation and 
Table II. Association between polypharmacy and comorbidity/pain management. p-Values less than 0.05 indicate statistical significance and are highlighted in bold.

\begin{tabular}{|c|c|c|c|c|}
\hline Parameter & $<5$ medications & 5-9 medications & $\geq 10$ medications & Significance level \\
\hline Charlson comorbidity index 0 & $62 \%$ & $35 \%$ & $3 \%$ & \\
\hline Charlson comorbidity index 1 & $28 \%$ & $48 \%$ & $24 \%$ & \\
\hline Charlson comorbidity index 2 & $31 \%$ & $39 \%$ & $29 \%$ & \\
\hline Charlson comorbidity index 3 & $10 \%$ & $49 \%$ & $43 \%$ & \\
\hline Charlson comorbidity index $>3$ & $11 \%$ & $43 \%$ & $46 \%$ & $p=0.0001$ \\
\hline No diabetes mellitus & $29 \%$ & $43 \%$ & $28 \%$ & \\
\hline Diabetes mellitus & $14 \%$ & $38 \%$ & $48 \%$ & $p=0.045$ \\
\hline No cardiac comorbidity & $39 \%$ & $39 \%$ & $22 \%$ & \\
\hline Cardiac comorbidity & $13 \%$ & $48 \%$ & $39 \%$ & $p=0.000002$ \\
\hline No COPD & $31 \%$ & $44 \%$ & $26 \%$ & \\
\hline COPD & $14 \%$ & $38 \%$ & $48 \%$ & $p=0.004$ \\
\hline No opioid analgesics & $42 \%$ & $41 \%$ & $16 \%$ & \\
\hline Opioid analgesics, no pump & $16 \%$ & $46 \%$ & $38 \%$ & \\
\hline Opioid analgesics, infusion pump & $0 \%$ & $20 \%$ & $80 \%$ & $p=0.0001$ \\
\hline
\end{tabular}

COPD, chronic obstructive pulmonary disease.

Table III. Recently published literature data.

\begin{tabular}{|c|c|c|}
\hline Reference & Setting, cohort & Results \\
\hline Woopen et al. 2016 (18) & $\begin{array}{l}\text { Individual participant data meta-analysis of data from } \\
\text { three phase II/III studies of the North-Eastern German } \\
\text { Society of Gynecological Oncology, chemotherapy } \\
\text { for recurrent ovarian cancer }(\mathrm{N}=1213)\end{array}$ & $\begin{array}{l}\text { An increasing number of medications was associated with } \\
\text { overall grade III/IV toxicity }(p<0.001) \text {, and hematological } \\
(p<0.001) \text { and non-hematological }(p<0.001) \text { toxicities. } \\
\text { Unplanned discontinuation of chemotherapy was not } \\
\text { influenced by medication. There was no association of } \\
\text { polypharmacy with overall survival. }\end{array}$ \\
\hline Park et al. 2016 (19) & $\begin{array}{l}229 \text { elderly head and neck cancer patients } \\
\text { who underwent definitive treatment }\end{array}$ & $\begin{array}{l}\text { Polypharmacy was not significantly associated with } \\
\text { treatment-related toxicity, but with modestly increased } \\
\text { prolonged hospitalization }(p=0.08) \text { and } \\
\text { non-cancer health events }(p=0.05)\end{array}$ \\
\hline Maggiore et al. 2014 (20) & $\begin{array}{l}500 \text { adults aged } 65 \text { and older with } \\
\text { cancer undergoing chemotherapy }\end{array}$ & $\begin{array}{l}\text { No association was found between number of daily } \\
\text { medications and toxicity or hospitalization. }\end{array}$ \\
\hline Hamaker et al. 2014 (21) & $\begin{array}{l}78 \text { elderly ( } \geq 65 \text { years) metastatic breast } \\
\text { cancer patients treated with first-line } \\
\text { palliative chemotherapy in a randomized trial }\end{array}$ & $\begin{array}{l}\text { Polypharmacy was the only individual factor } \\
\text { significantly associated with toxicity }(p=0.001) \text {. }\end{array}$ \\
\hline
\end{tabular}

stomach ulcer prophylaxis. Therefore, use of five or more daily medications is not always inappropriate.

\section{References}

1 Tsilidis KK, Papadimitriou N, Capothanassi D, Bamia C, Benetou V, Jenab M, Freisling H, Kee F, Nelen A, O’Doherty MG, Scott A, Soerjomataram I, Tjønneland A, May AM, Ramón Quirós J, Pettersson-Kymmer U, Brenner H, Schöttker B, Ordóñez-Mena JM, Karina Dieffenbach A, Eriksson S, Bøgeberg Mathiesen E, Njølstad I, Siganos G, Wilsgaard T, Boffetta P, Trichopoulos D and Trichopoulou A: Burden of cancer in a large consortium of prospective cohorts in Europe. J Natl Cancer Inst 108: epub, 2016.

2 Semrau S, Zettl H, Hildebrandt G, Klautke G and Fietkau R: Older patients with inoperable non-small cell lung cancer: longterm survival after concurrent chemoradiotherapy. Strahlenther Onkol 190: 1125-1132, 2014.

3 Nieder C, Mannsåker B, Dalhaug A, Pawinski A and Haukland E: Palliative radiotherapy in cancer patients with increased serum C-reactive protein level. In Vivo 30: 581-586, 2016.

4 Nieder C, Engljähringer K and Angelo K: Impact of comorbidity on survival after palliative radiotherapy. Strahlenther Onkol 190: $1149-1153,2014$. 
5 Adamietz IA, Micke O, Popp W and Sack H: Evaluating the attendance of medical staff and room occupancy during palliative radiotherapy. Strahlenther Onkol 190: 781-785, 2014.

6 Oehlke O, Wucherpfennig D, Fels F, Frings L, Egger K, Weyerbrock A, Prokic V, Nieder C and Grosu AL: Whole brain irradiation with hippocampal sparing and dose escalation on multiple brain metastases: Local tumour control and survival Strahlenther Onkol 191: 461-469, 2015.

7 Janssen S, Bolm L, Käsmann L, Bartscht $\mathrm{T}$ and Rades D: Palliative radiation therapy for spinal cord compression from metastatic soft tissue sarcoma. In Vivo 30: 529-531, 2016.

8 Martinez-Tapia C, Canoui-Poitrine F, Bastuji-Garin S, Soubeyran P, Mathoulin-Pelissier S, Tournigand C, Paillaud E, Laurent $\mathrm{M}$ and Audureau E; ELCAPA Study Group: Optimizing the G8 screening tool for older patients with cancer: Diagnostic performance and validation of a six-item version. Oncologist 21: 188-195, 2016.

9 LeBlanc TW, McNeil MJ, Kamal AH, Currow DC and Abernethy AP: Polypharmacy in patients with advanced cancer and the role of medication discontinuation. Lancet Oncol 16: e333-341, 2015

10 Nightingale G, Hajjar E, Swartz K, Andrel-Sendecki J and Chapman A: Evaluation of a pharmacist-led medication assessment used to identify prevalence of and associations with polypharmacy and potentially inappropriate medication use among ambulatory senior adults with cancer. J Clin Oncol 33: 1453-1459, 2015.

11 Charlson ME, Pompei P, Ales KL and MacKenzie CR: A new method of classifying prognostic comorbidity in longitudinal studies: development and validation. J Chronic Dis 40: 373-383, 1987.

12 Douglas E and McMillan DC: Towards a simple objective framework for the investigation and treatment of cancer cachexia: the Glasgow Prognostic Score. Cancer Treat Rev 40: 685-691, 2014.

13 Turner JP, Jamsen KM, Shakib S, Singhal N, Prowse R and Bell JS: Polypharmacy cut-points in older people with cancer: how many medications are too many? Support Care Cancer 24: 1831$1840,2016$.

14 Kotlinska-Lemieszek A, Paulsen O, Kaasa S and Klepstad P: Polypharmacy in patients with advanced cancer and pain: a European cross-sectional study of 2282 patients. J Pain Symptom Manage 48: 1145-1159, 2014.

15 Turner JP, Shakib S, Singhal N, Hogan-Doran J, Prowse R, Johns S and Bell JS: (2014) Prevalence and factors associated with polypharmacy in older people with cancer. Support Care Cancer 22: 1727-1734. Erratum in 22: 1735, 2014.
16 Prithviraj GK, Koroukian S, Margevicius S, Berger NA, Bagai R and Owusu C: Patient characteristics associated with polypharmacy and inappropriate prescribing of medications among older adults with cancer. J Geriatr Oncol 3: 228-237, 2012.

17 Hübner J, Muenstedt K, Muecke R, Micke O, Stoll C, Kleeberg UR, Buentzel J, Dennert G and Prott FJ: Counseling cancer patients on complementary and alternative medicine. Background, theory, and implementation of nationwide counseling facilities. Strahlenther Onkol 189: 613-617, 2013.

18 Woopen H, Richter R, Ismaeel F, Chekerov R, Roots I, Siepmann $\mathrm{T}$ and Sehouli J: The influence of polypharmacy on grade III/IV toxicity, prior discontinuation of chemotherapy and overall survival in ovarian cancer. Gynecol Oncol 140: 554-558, 2016.

19 Park JW, Roh JL, Lee SW, Kim SB, Choi SH, Nam SY and Kim SY: Effect of polypharmacy and potentially inappropriate medications on treatment and posttreatment courses in elderly patients with head and neck cancer. J Cancer Res Clin Oncol 142: 1031-1040, 2016.

20 Maggiore RJ, Dale W, Gross CP, Feng T, Tew WP, Mohile SG, Owusu C, Klepin HD, Lichtman SM, Gajra A, Ramani R, Katheria V, Zavala L and Hurria A; Cancer and Aging Research Group: Polypharmacy and potentially inappropriate medication use in older adults with cancer undergoing chemotherapy: effect on chemotherapy-related toxicity and hospitalization during treatment. J Am Geriatr Soc 62: 1505-1512, 2014.

21 Hamaker ME, Seynaeve C, Wymenga AN, van Tinteren H, Nortier JW, Maartense E, de Graaf H, de Jongh FE, Braun JJ, Los M, Schrama JG, van Leeuwen-Stok AE, de Groot SM and Smorenburg $\mathrm{CH}$ : Baseline comprehensive geriatric assessment is associated with toxicity and survival in elderly metastatic breast cancer patients receiving single-agent chemotherapy: results from the OMEGA study of the Dutch breast cancer trialists' group. Breast 23: 81-87, 2014.

22 McLean S, Sheehy-Skeffington B, O'Leary N and O'Gorman A: Pharmacological management of co-morbid conditions at the end of life: is less more? Ir J Med Sci 182: 107-112, 2013.
Received December 1, 2016

Revised January 10, 2017

Accepted January 12, 2017 